\title{
Peripheral $T$ cell lymphoma with a regulatory $T$ cell phenotype: a Mexican case not associated with HTLV-1 virus infection
}

\author{
Francisco Llamas-Gutierrez • Gerardo Espinoza-Macias • \\ Yvette Neme-Yunes • Ricardo Aguilar-Guadarrama • \\ Gladys Agreda-Vásquez • Carmen Lome-Maldonado
}

Received: 14 December 2013 / Accepted: 21 February 2014 / Published online: 5 March 2014

(C) Springer-Verlag Berlin Heidelberg 2014

\begin{abstract}
Peripheral T cell lymphomas are aggressive neoplasms with an overall bad prognosis. As occurred with B cell lymphomas, some $\mathrm{T}$ cell lymphomas have been correlated with a normal $\mathrm{T}$ cell counterpart. According to the actual WHO classification of tumors of hematopoietic and lymphoid tissues, the only $\mathrm{T}$ cell lymphoma characterized by a $\mathrm{T}_{\text {reg }}$ phenotype is adult $\mathrm{T}$ cell leukemia/ lymphoma (ATCLL), an entity defined by its etiologic association with HTLV-1 infection. We present a case of peripheral $\mathrm{T}$ cell lymphoma with a Treg phenotype not associated with HTLV-1 infection. We describe its pathological and clinical characteristics and discuss the presence of a $\mathrm{T}_{\text {reg }}$ phenotype in $\mathrm{T}$ cell lymphomas.
\end{abstract}

Keywords T cell lymphoma $\cdot \mathrm{T}_{\text {reg }} \cdot \mathrm{FOXP} 3$

\section{Introduction}

Peripheral T cell lymphomas (PTCL) are aggressive neoplasm's characterized by an overall poor prognosis.

Regulatory $\mathrm{T}$ cells $\left(\mathrm{T}_{\text {regs }}\right)$ are a subpopulation of $\mathrm{T}$ helper lymphocytes specialized in suppressing inflammatory responses. They suppress proliferation and activation of other $T$ cells, maintaining the balance between immunity and tolerance. Their presence as part of the inflammatory reaction to some neoplastic disorders has been associated with a weaker cytotoxic immunologic response to tumors but also, for some entities, with a better prognosis [1-3]. $\mathrm{T}_{\text {regs }}$ are characterized by the expression of the forkhead transcription factor family

F. Llamas-Gutierrez $(\bowtie) \cdot$ G. Espinoza-Macias · Y. Neme-Yunes • R. Aguilar-Guadarrama · G. Agreda-Vásquez $\cdot$ C. Lome-Maldonado Instituto Nacional de Ciencias Médicas y Nutrición Salvador Zubiran, Mexico Vasco de Quiroga 15, C.P.14000 Mexico, Distrito Federal, Mexico

e-mail: xavre@hotmail.com member: FOXP3; they also express surface cell markers like CD4 and CD25, all easily detected by immunohistochemical methods [3].

As occurred with B cell lymphomas, efforts have been made to correlate PTCLs with a normal $\mathrm{T}$ cell counterpart. For example, anaplastic large cell lymphoma (ALCL), enteropathy-associated $\mathrm{T}$ cell lymphoma (EATL), and subcutaneous panniculitis-like $\mathrm{T}$ cell lymphoma are thought to derive from an effector/memory $\mathrm{CD}^{+} \mathrm{T}$ cell, mycosis fungoides from effector $\mathrm{CD}^{+} \mathrm{T}$ cells, and angioimmunoblastic lymphoma (AIL) from follicular helper $\left(\mathrm{T}_{\mathrm{FH}}\right) \mathrm{T}$ cells [4]. Exemptions are not rare and phenotypic plasticity is a well-recognized problem when trying to classify $\mathrm{T}$ cell lymphomas.

As a group, PTCL not otherwise specified (NOS) remain poorly understood. While early studies failed to classify PTCL NOS according to a CD8/cytotoxic or a CD4/helper immunophenotype, a gene expression profiling (GEP) study published in 2007 by Piccaluga et al. found that overall, the PTCL-NOS gene expression pattern was more similar to activated CD4 T cells, with only a minority of cases resembling activated CD8 T cells. Interestingly, immunophenotypic analysis for CD4 and CD8 did not correlate with different GEP groups $[5,6]$.

According to the actual WHO classification of tumors of hematopoietic and lymphoid tissues, the only $\mathrm{T}$ cell lymphoma characterized by a $T_{\text {reg }}$ phenotype is adult $T$ cell leukemia/lymphoma (ATLL), an entity defined by its etiologic association with HTLV-1 infection; in spite of this some cutaneous $\mathrm{T}$ cell lymphomas (CTCL) and at least three cases of PTCL NOS with a $T_{\text {reg }}$ phenotype have been reported (one from Germany and two from South America), these cases were not associated with HTLV-1 infection [7-16].

We report a case of PTCL NOS showing a bona fide $T_{\text {reg }}$ phenotype, and review the pertinent literature. 


\section{Clinical history}

A 61-year-old woman presented with a 2-month history of intermittent abdominal pain and lower limb edema. Physical examination revealed a palpable abdominal mass. The CT-scan documented a circumferential wall thickening of the small-bowel that was $25-\mathrm{cm}$ long affecting the proximal and middle jejunum. Multiple mesenteric, aortic, and retroperitoneal lymphadenopathies were also noted; hepatosplenomegaly was absent. No history of chronic diarrhea, malabsorption, weight loss, or fever was reported.

Complete blood count showed $4.6 \times 10^{9} / \mathrm{L}$ leukocytes, with a normal differential hemoglobin of $8 \mathrm{~g} / \mathrm{dL}$, and a platelet count of $455 \times 10^{9} / \mathrm{L}$. The liver enzymes were within normal limits, and the lactate dehydrogenase level was $130 \mathrm{IU} / \mathrm{mL}$.

Biopsies from the intestinal lesion were reported as PTCL, NOS, with a $T_{\text {reg }}$ phenotype. The bone marrow biopsy did not show infiltration. Her Ann Arbor Stage was III AE with a lowintermediate International Prognostic Index risk and a good performance status.

The patient was treated with standard doses of CHOEP and achieved a complete remission after six cycles. Twelve months later, she presented with fever, weight loss, and diaphoresis; a colonic recurrence was documented and treated by ICE (ifosfamide, carboplatin, and etoposide). The patient suffered from severe ifosfamide toxicity and nonconvulsive epilepsy that was aggravated by pneumonia. She died 21 months after the diagnosis.

\section{Materials and methods}

Routine hematoxylin and eosin (H\&E) sections were prepared using standard techniques from formalin-fixed paraffin blocks. Immunohistochemical analyses included the following monoclonal antibodies: CD3, CD20, LMP-1 (BioSB) CD4, CD7, CD5, CD30, TIA 1 (Biocare), CD56 (Dako), CD8 (NeoMarkers), PD-1 (cell marque), CD25 (Novocastra), CD10, BCL-6, Granzyme B, and FOXP3 (Abcam).

In situ hybridization for EBV-encoded RNA (EBER) was performed on the biopsy. The EBER detection kit was purchased from Dako (Glostrup, Denmark). The detection process was conducted according to the manufacturer's instructions.

T cell clonality: DNA was extracted from formalin-fixed, paraffin-embedded tissue sections. This purified DNA was used to assay for clonal rearrangements of the T cell receptor $(T C R) \gamma$ genes by polymerase chain reaction (PCR) using the method described by McCarthy et al. [17].

Molecular detection of HTLV-1: DNA was extracted from formalin-fixed, paraffin-embedded tissue sections. PCR was performed using primers that detect the TAX and long terminal repeat (LTR) regions of HTLV-1 as follows:

\section{HTLV-tax-F: 5'-GGATACCCAGTCTACGTGTTTG-3' HTLV-tax-R: 5'-CGGAACATTGGTGAGGAAGGC-3' HTLV-LTR-F: 5'-CCAGACTAAGGCTCTGACGTCT C-3' \\ HTLV-LTR-R: 5'-CCTGAGCTCTAAACTTACCTAG ACG-3'}

Products were examined using polyacrylamide gel electrophoresis [18].

\section{Results}

The jejunal endoscopic biopsy revealed a monotonous lymphoma diffusely infiltrating and expanding the lamina propria (Fig. 1). The tumor cells were large- to medium-sized lymphocytes with round nuclei, fine chromatin, and 1-3 visible nucleoli. Mitotic activity was high. A moderate villous atrophy without ulceration was noted; interestingly, intraepithelial lymphocytes (IELs) were nearly absent and tumor-infiltrating lymphocytes were sparse. All biopsies lacked normal intestinal mucosa. The colonic recurrence showed the same cohesive morphology with few tumor-infiltrating lymphocytes.

Immunohistochemically, the tumor cells expressed $\mathrm{T}$ cell markers (CD3, CD5, and CD7) and a $\mathrm{T}_{\text {reg }}$ phenotype characterized by diffuse positivity for CD4, CD25, and FOXP3. A $\mathrm{T}_{\mathrm{FH}}$ immunophenotype was explored using PD-1, BCL-6, and CD10; all three antibodies were negative. Cytotoxic markers (CD8, Granzyme B, and TIA-1) were negative within the tumor and positive in IELs. Tumor infiltrating lymphocytes included $\mathrm{B}$ and $\mathrm{T}$ mature lymphocytes. Tumor cells were also negative for CD20, CD56, CD30, LMP-1, and EBER in situ hybridization.

Analysis by PCR of paraffin-embedded tissue showed clonal rearrangements of the TCR- $\gamma$ (data not shown). A PCR for HTLV-1 was performed using DNA extracted from negative and positive controls and the patient's biopsy. While a band at the correct position with both primer sets was found in the positive control, no amplification was found in the patient's specimen, indicating that this lymphoma is not associated with HTLV-1 infection (Fig. 2).

The differential diagnosis included T/NK T cell lymphoma, a common entity in Central/South America, characterized by frequent extranodal presentation, yet negativity for CD56, cytotoxic markers, and EBER in situ hybridization, excluded it.

Moderate villous atrophy and large cell morphology seen in the jejunal biopsy could suggest a diagnosis of EATL; neither type I nor type II variants are characterized by a CD4 immunophenotype, the first being generally CD4-, CD8-, $\mathrm{CD} 30^{+}$and the second $\mathrm{CD} 4-, \mathrm{CD} 8^{+}, \mathrm{CD} 56^{+}$; both types usually 
Fig. 1 Jejunal biopsy. a Diffuse lymphomatous infiltration $(H \& E, \times 100)$. b Detail of the monotonous large cells with fine chromatin and visible nucleoli; tumor infiltrating lymphocytes are rare $(\mathrm{H} \& \mathrm{E}, \times 400)$. CD3, CD4, FOXP3, and CD25 (IHC, $\times 200)$

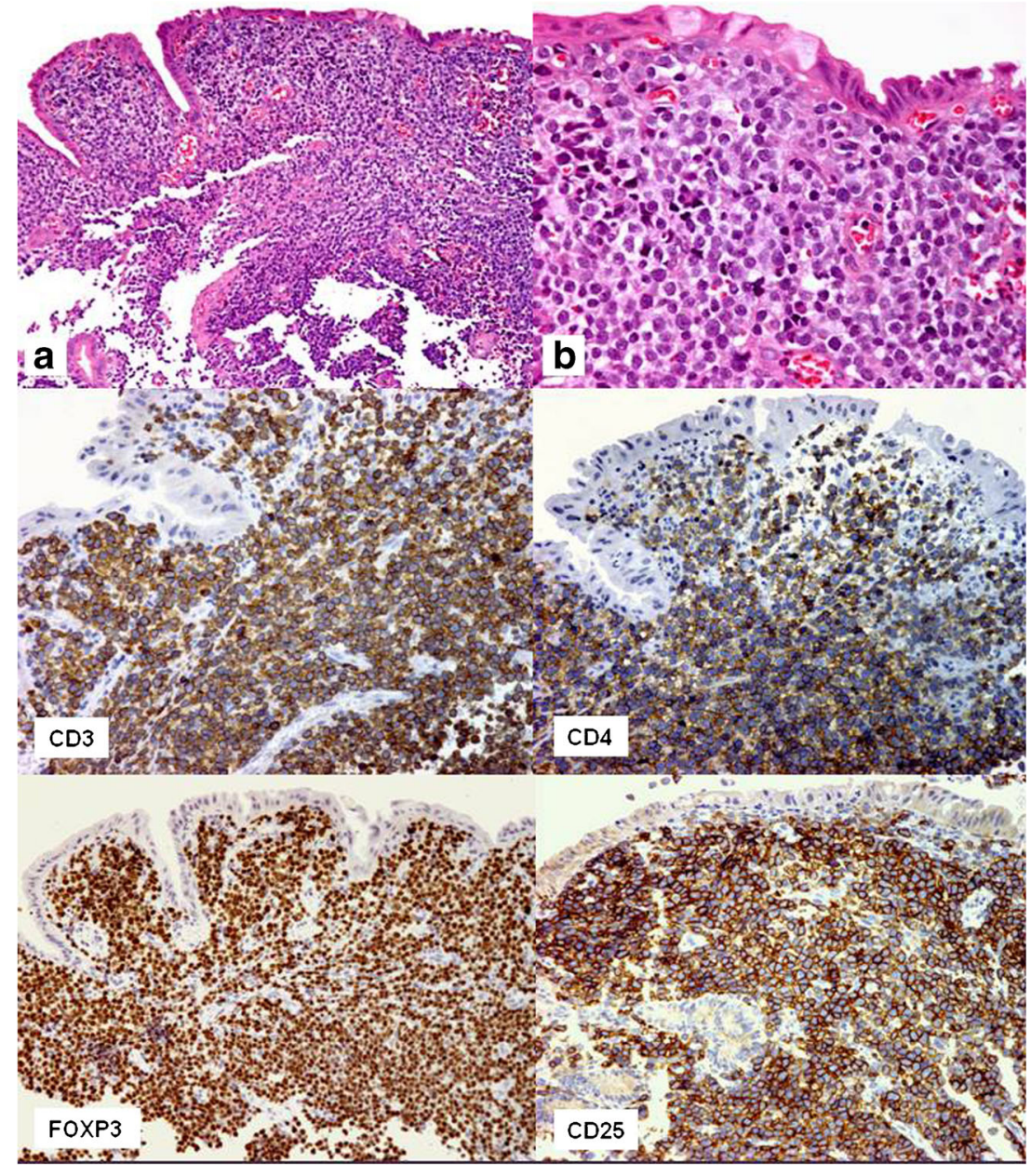

express cytotoxic granule associated proteins like TIA1 and Granzyme B, which were negative in our case. While IELs in type I EATL may have an aberrant CD4-, CD8-, CD56immunophenotype, type II EATL IELs have a characteristic CD4-, $\mathrm{CD}^{+}, \mathrm{CD}^{+} 6^{+}$immunophenotype; IELs in our case had a normal CD4-, $\mathrm{CD}^{+}, \mathrm{CD} 56-$ immunophenotype. Moreover,

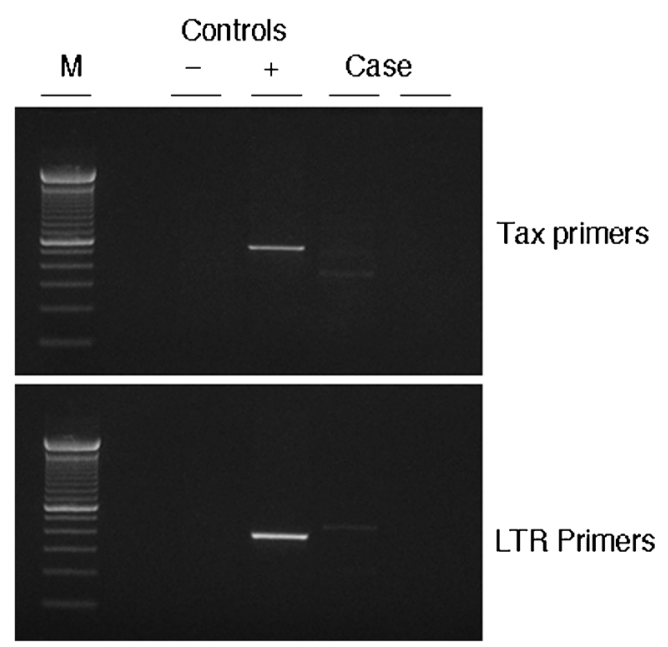

Fig. 2 Molecular analysis for HTLV-1 the lack of chronic diarrhea or malabsorption history discouraged this diagnosis. Negativity for CD30 excluded ALCL. [7, 19].

Recently, cases of primary small intestinal $\mathrm{CD}^{+} \mathrm{T}$ cell lymphomas with an indolent behavior have been described; all reported cases, originally diagnosed as refractory celiac disease, presented with diarrhea and weight loss, which was absent in our case. These cases were composed of small- to medium-sized lymphocytes with a low proliferative index, infiltrating the lamina propria, which is concordant with an indolent behavior; moreover, all cases were negative for $\mathrm{T}_{\text {reg }}$ markers (CD25 Foxp3) and featured CD4 ${ }^{+}$IELs [20, 21]. Morphologic, immunophenotipic, and clinical differences excluded this diagnosis.

\section{Discussion}

We describe a case of PTCL NOS with a full $\mathrm{T}_{\text {reg }}$ phenotype that histologically resembles other three cases previously reported (from Peru and Germany) (Table 1). Morphologically, all cases share a monotonous neoplastic infiltrate constituted by cohesive large size, "immunoblastic-like" cells, with prominent nucleoli and 


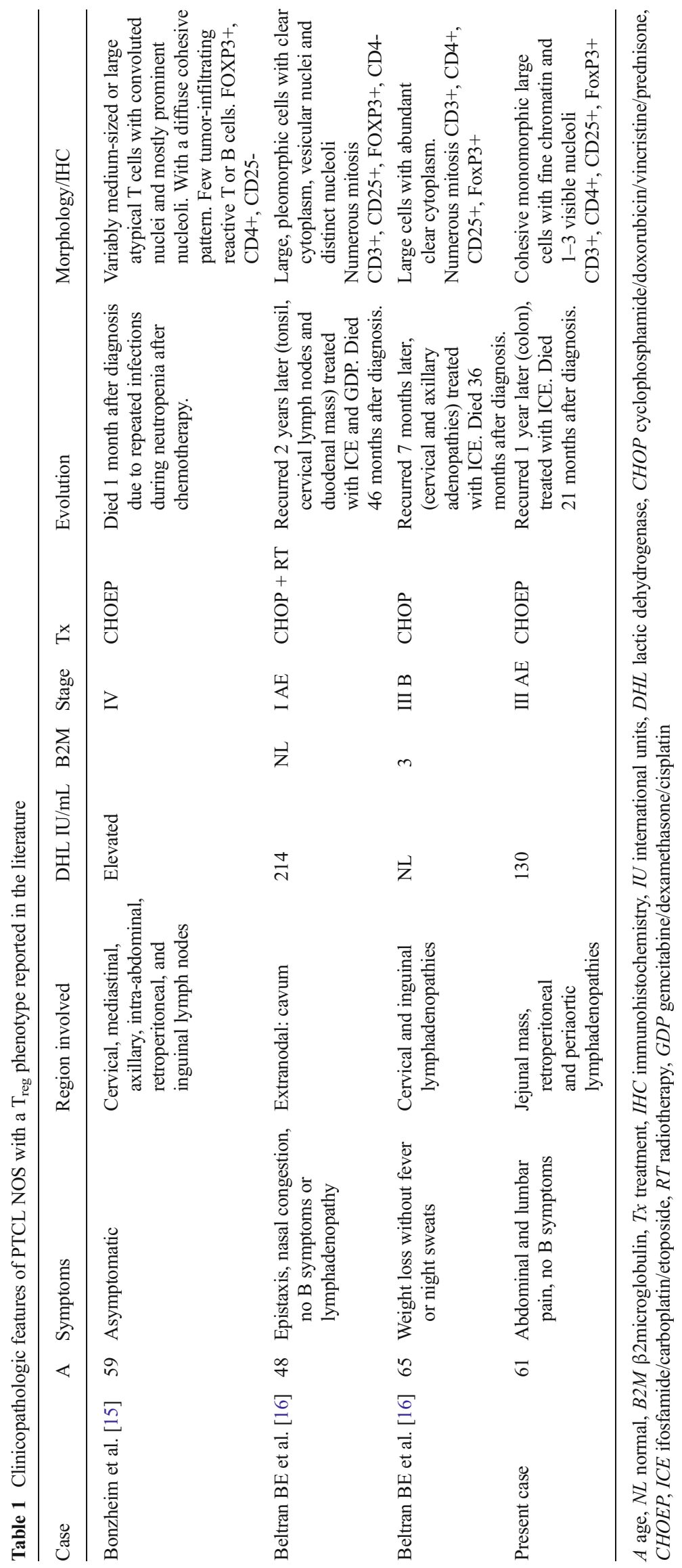


fine chromatin. Characteristically, the reactive infiltrate was scant.

Several studies have associated ATLL to a $T_{\text {reg }}$ phenotype, postulating $\mathrm{T}_{\text {regs }}$ as the normal counterpart for this lymphoma [7, 22-26]. Recently, some groups have challenged this point of view, considering that HTLV-1 can induce via its Tax protein both an increased circulating nontumoral $\mathrm{T}_{\text {reg }}$ population and an increased FOXP3 expression in infected cells [27]. Another study found that only $36 \%$ (60 of 169) of ATLL cases from Japan showed FOXP3 expression in lymphoma cells [28], supporting the idea that the $\mathrm{T}_{\text {reg }}$ phenotype could be induced rather than being present from the beginning [27].

Our case lacked most of the clinical manifestations expected for the chronic, smoldering, acute, or lymphomatous forms of ATLL. Lymphocytosis with peripheral blood circulating cells, cutaneous lesions, bone lesions, hypercalcemia, hepatosplenomegaly, and bone marrow infiltration were all absent [7].

The prevalence of HTLV-1 infection in the general Mexican population has not yet been defined. In America, it is known that Brazil, Colombia, Peru, and the Caribbean are endemic areas $(2-10 \%$ of their healthy adult population is infected). The virus has also been reported in Ecuador, Paraguay, Chile, and Argentina [29]. The largest survey done in Mexican population analyzed 1,078 serum samples of different risk groups, from 6 Mexican states. Of these, only 12 were positive by agglutination test and none was positive by Western blot analysis; other studies have confirmed this low prevalence in the north of the country [30, 31]. All these factors and a negative PCR test for HTLV-1 infection discouraged a diagnosis of ATLL.

Bonzheim et al. analyzed 83 PTCL: 32 PTCL NOS, 23 AIL, 20 ALCL (14 ALK - and 6 ALK+), and 8 other types of T cell lymphoma ( 2 cutaneous, 4 intestinal, 1 hepatosplenic, and 1 T/NK-cell lymphoma, nasal type), and found only 1 case with diffuse FOXP3 immunohistochemical positivity. Histologically, their case was also characterized by a diffuse growth pattern of medium and large atypical $\mathrm{T}$ cells with prominent nucleoli, being originally diagnosed, according to the Kiel classification, as the immunoblastic variant of PTCL-NOS. As in our case, this case showed a scant reactive inflammatory background, which the authors remarked as unusual among PTCL, evoking a possible inhibitory roll derived from a retained $\mathrm{T}_{\text {reg }}$ cell function of the neoplastic cells.

Immunohistochemically, their case was diffusely positive for FOXP3 and CD4 while negative for CD25. As in the present case, HTLV-1 proviral DNA was not amplifiable by PCR. The patient died during the chemotherapy-induced neutropenic phase due to repeated infections 1 month after the diagnosis. The authors speculated that $T_{\text {reg }}$ function might have significantly suppressed antitumor immunity, which contributed to progression. They concluded that this rare phenotype could represent an adverse risk factor in PTCL-NOS [15].
Two similar cases from Peru were reported by Brady et al.; in both cases, the lymphoma was composed of large cohesive cells, with clear cytoplasm, vesicular nuclei, and visible nucleoli. The first case was positive for FOXP $3+$ and $\mathrm{CD} 25+$ but lacked CD4, while the second case showed the same full $\mathrm{T}_{\text {reg }}$ phenotype present in our case. These cases, as described in other $\mathrm{T}$ cell lymphomas, showed large Reed-Sternberg-like cells positive for EBER in situ hybridization; EBV activation being possibly induced by a $T_{\text {reg-associated immunosuppres- }}$ sion $[16,32,33]$. The present case lacked Reed-Sternberg-like cells, EBV infection, or other signs of immunosuppression.

These four cases of PTCL NOS with a $T_{\text {reg }}$ phenotype showed variable clinical features; they all had different clinical stages, nodal and/or extranodal manifestations, and presented with or without B symptoms. The three cases from Central/ South America showed a complete initial remission followed by variable progression-free survivals ( 7 months, 1 year, and 2 years); the three cases relapsed and patients died 36, 21, and 46 months after diagnosis, respectively. None of these cases reached a 5-year survival, known to be of $30 \%$ in PTCL NOS, thereby suggesting a still worse prognosis for this phenotype [19].

$\mathrm{A} \mathrm{T}_{\text {reg }}$ phenotype has also been claimed in some CTCL and ALCL. Berger et al. described in vitro transformation of CTCL cells to a $\mathrm{T}_{\text {reg }}$ phenotype after stimulation by immature dendritic cells charged with CTCL apoptotic debris [8]. A further study found increased levels of FoxP3 in peripheral blood mononuclear cells (PBMCs) of 3 of 12 HTLV-1 negative CTCL patients by quantitative real-time PCR [34]. Another study using the same technique analyzed 28 CTCL, 25 Sezary syndromes (SS), and $3 \mathrm{MF}$, and found $6 \mathrm{SS}$ cases with extremely high expression levels for FoxP3 and CD25 [11]. A German study found FOXP3 expression in 4 of $5 \mathrm{MF}$ with large cell transformation; these results are hampered by an exclusive cytoplasmic FOXP3 positivity seen in all figures [13].

Further studies using immunohistochemistry and FACS have showed that CTCL are generally negative for FOXP3 and that the proportion of $\mathrm{T}_{\text {regs }}$ in dermal infiltrates and peripheral blood varies among cases; Klemke et al. found significantly lower numbers of $\mathrm{T}_{\text {regs }}$ in biopsies and peripheral blood of patients with SS, carrying a worse prognosis than MF [35]. Gjerdrum et al. analyzed 86 patients with MF and CTCL unspecified and found that all cases were negative for FOXP3; nevertheless, they found that cases with increasing numbers of tumor infiltrating $\mathrm{T}_{\text {regs }}$ had a better prognosis [9].

A study from Denmark found FOXP3 immunohistochemical expression in 1 of 13 cutaneous ALCL (C-ALC) analyzed; in this case, staining was intense, nuclear, and diffuse. They also found rare positive tumor cells in a case of lymphomatoid papulosis (LyP) and two other C-ALCL cases [12].

FOXP3 expression has been also reported in ALCL; Kasprzycka et al. demonstrated elevated expression in 4 of 4 ALK + ALCL cell lines by real-time quantitative PCR; they 
also showed that lymphoid cells transfected with NPM/ALK acquired a $T_{\text {reg }}$ cell phenotype [36]. Bonzheim et al. described FOXP3 positivity in 4 of 6 ALK + ALCL and in 1 of 14 ALKALCL. In these cases, only 20 to $30 \%$ of tumor cells showed weak and variable immunohistochemical positivity for FOXP3, which was not followed by positivity for other $T_{\text {reg }}$ markers. In view of these findings, the authors considered FoxP3 expression as aberrant instead of a part of a true $\mathrm{T}_{\text {reg }}$ phenotype [15].

We report a fourth case of PTCL NOS with a bona fide $T_{\text {reg }}$ phenotype not associated with HTLV-1 infection. We agree with previous reports that the morphology and immunophenotype of this tumor could eventually place it as a separate entity. In view that three of these cases come from Central/South America, further studies are necessary to establish the real frequency of this phenotype in PTCL NOS from this population.

Conflict of interest The authors declare they have no conflict of interest.

\section{References}

1. Mai J, Wang H, Yang XF (2010) Thelper 17 cells interplay with CD4 + CD25highFoxp3+ Tregs in regulation of inflammations and autoimmune diseases. Front Biosci 15:986-1006

2. Mittal S, Marshall NA, Duncan L, Culligan DJ, Barker RN, Vickers MA (2008) Local and systemic induction of CD4 + CD25+ regulatory $\mathrm{T}$ cell population by non-Hodgkin lymphoma. Blood 111(11): 5359-5370

3. Roncador G, Garcia JF, Garcia JF, Maestre L, Lucas E, Menarguez J, Ohshima K, Nakamura S, Banham AH, Piris MA (2005) FOXP3, a selective marker for a subset of adult T-cell leukaemia/lymphoma. Leukemia 19:2247-2253

4. de Leval L, Gaulard P (2011) Pathology and biology of peripheral Tcell lymphomas. Histopathology 58(1):49-68

5. Piccaluga PP et al (2007) Gene expression analysis of peripheral T cell lymphoma, unspecified, reveals distinct profiles and new potential therapeutic targets. J Clin Invest 117(3):823-834

6. Pileri SA, Piccaluga PP (2012) New molecular insights into peripheral T cell lymphomas. J Clin Invest 122(10):3448-3455

7. Jaffe ES, Harris NL, Stein H, Campo E, Pileri SA, Swerdlow SH (2008) Introduction and overview of the classification of the lymphoid neoplasms. In: Swerdlow S (ed) WHO classification of tumors of hematopoietic and lymphoid tissues. International Agency For Research On Cancer, Lyon, France, pp 158-166

8. Berger CL, Tigelaar R, Cohen J et al (2005) Cutaneous T-cell lymphoma: malignant proliferation of T-regulatory cells. Blood 105:1640-1647

9. Gjerdrum LM, Woetmann A et al (2007) FOXP3+ regulatory T cells in cutaneous T-cell lymphomas: association with disease stage and survival. Leukemia 21:2512-2518

10. Berger CL, Tigelaar R et al (2005) Cutaneous T-cell lymphoma: malignant proliferation of T-regulatory cells. Blood 105(4):1640-1647

11. Capriotti E, Vonderheid EC et al (2008) Expression of T-plastin, FoxP3 and other tumor-associated markers by leukemic T-cells of cutaneous T-cell lymphoma. Leuk Lymphoma 49(6):1190-1201

12. Gjerdrum LM, Woetmann A et al (2008) FOXP3 positive regulatory T-cells in cutaneous and systemic CD30 positive T-cell lymphoproliferations. Eur J Haematol 80:483-489
13. Hallermann C, Niermann C et al (2007) Regulatory T-cell phenotype in association with large cell transformation of mycosis fungoides. Eur J Haematol 78:260-263

14. Marzano AV, Vezzoli P et al (2009) Primary cutaneous T-cell lymphoma expressing FOXP3: a case report supporting the existence of malignancies of regulatory T cells. J Am Acad Dermatol 61:348-355

15. Bonzheim I, Geissinger E, Tinguely M, Roth S, Grieb T, Reimer P, Wilhelm M, Rosenwald A, Müller-Hermelink HK, Rüdiger T (2008) Evaluation of FoxP3 expression in peripheral T-cell lymphoma. Am J Clin Pathol 130:613-619

16. Beltran BE, Morales D, Quinones P et al (2012) Peripheral T-cell lymphoma with a regulatory T-cell phenotype: report of a nodal and an extranodal case from Peru. Appl Immunohistochem Mol Morphol 20(2):196-200

17. McCarthy KP, Sloane JP, Kabarowski JHS (1992) A simplified method of detection of clonal rearrangements of the T-cell receptor$\gamma$ chain gene. Diagn Mol Pathol 1:173-179

18. Costa JM, Sumita LM, Segurado AC (2006) Non-radioisotope detection of pol sequences of HTLV-1 proviral DNA: standardisation and sensitivity analysis. J Virol Methods 137:29-33

19. Jaffe ES, Harris NL, Vardiman JW, Campo E, Arber DA (2011) Hematopathology. Saunders Elsevier, Philadelphia

20. Margolskee E, Jobanputra V, Lewis SK (2013) Indolent small intestinal CD4+ T-cell lymphoma is a distinct entity with unique biologic and clinical features. PLoS One 8(7):e68343

21. Malamut G, Meresse B, Kaltenbach S et al. (2013) Small intestinal CD4+ T-cell lymphoma is a heterogenous entity with common pathology features. Clin Gastroenterol Hepatol. doi:10.1016/j.cgh. 2013.11.028

22. Karube K, Ohshima K, Tsuchiya T et al (2004) Expression of FoxP3, a key molecule in $\mathrm{CD} 4 \mathrm{CD} 25$ regulatory $\mathrm{T}$ cells, in adult T-cell leukaemia/lymphoma cells. Br J Haematol 126:81-84

23. Ishida T, Iida S, Akatsuka Y et al (2004) The CC chemokine receptor 4 as a novel specific molecular target for immunotherapy in adult T-cell leukemia/lymphoma. Clin Cancer Res 10:7529 7539

24. Kohno T, Yamada Y, Akamatsu N et al (2005) Possible origin of adult T-cell leukemia/lymphoma cells from human T lymphotropic virus type-1-infected regulatory $\mathrm{T}$ cells. Cancer Sci 96:527533

25. Matsubara Y, Hori T, Morita R et al (2005) Phenotypic and functional relationship between adult T-cell leukemia cells and regulatory $\mathrm{T}$ cells. Leukemia 19:482-483

26. Roncador G, Garcia JF, Garcia JF et al (2005) FOXP3, a selective marker for a subset of adult T-cell leukaemia/lymphoma. Leukemia 19:2247-2253

27. Bangham CR, Toulza F et al (2011) Adult T cell leukemia/ lymphoma: FoxP3 $(+)$ cells and the cell-mediated immune response to HTLV-1. Adv Cancer Res 111:163-182

28. Karube K, Aoki R et al (2008) The relationship of FOXP3 expression and clinicopathological characteristics in adult T-cell leukemia/ lymphoma. Mod Pathol 21:617-625

29. Gotuzzo E, Verdonck K (2004) HTLV-1: clinical impact of a chronic infection. In: Knobler SL, O'Connor S, Lemon SM, Najafi M (eds) The Infectious Etiology of Chronic Diseases: Defining the Relationship, Enhancing the Research, and Mitigating the Effects, 1 st edn. The National Academies Press, Washington DC, pp 110119

30. Trejo-Avila LM, Fuentes-Pensamiento R et al (1996) Seroprevalence of HTLV-I/II in blood donors in Monterrey, Mexico. Arch Med Res 27(1):97-99

31. Flores-Castañeda MS, Salinas-Carmona MC et al (1992) Antibodies against human T-cell lymphotropic viruses in subjects at high risk for HIV in Monterrey. Rev Investig Clin 44(1):37-41

32. Barry TS, Jaffe ES, Sorbara L et al (2003) Peripheral T-cell lymphomas expressing CD30 and CD15. Am J Surg Pathol 27:1513-1522 
33. Quintanilla-Martinez L, Fend F, Moguel LR et al (1999) Peripheral Tcell lymphoma with Reed-Sternberg-like cells of B-cell phenotype and genotype associated with Epstein-Barr virus infection. Am J Surg Pathol 23:1233-1240

34. Walsh PT, Benoit BM, Wysocka M et al (2006) A role for regulatory T cells in cutaneous T-cell lymphoma: induction of a CD4 + CD25 + Foxp3+ T-cell phenotype associated with HTLV-1 infection. J Investig Dermatol 126:690-692
35. Klemke CD, Fritzsching B, Franz B, Kleinmann EV, Oberle N, Poenitz N et al (2006) Paucity of FOXP3 + cells in skin and peripheral blood distinguishes Sezary syndrome from other cutaneous T-cell lymphomas. Leukemia 20:1123-1129

36. Kasprzycka M, Marzec M, Liu X et al (2006) Nucleophosmin/ anaplastic lymphoma kinase (NPM/ALK) oncoprotein induces the T regulatory cell phenotype by activating STAT3. Proc Natl Acad Sci USA 103:9964-9969 